\title{
IMPLEMENTASI PENDIDIKAN HAK ASASI MANUSIA DALAM DUNIA PENDIDIKAN SEKOLAH DASAR
}

\author{
Sinta Galih Pertiwi \& Yayuk Hidayah \\ Universitas Ahmad Dahlan \\ yayuk.hidayah@pgsd.uad.ac.id
}

\begin{abstract}
Abstrak
Implementasi pendidikan HAM dalam dunia pendidikan Sekolah Dasar adalah salah satu bagian yang penting dalam pendidikan di Sekolah Dasar. Tujuan penelitian ini adalah dari keinginan penulis dalam mengetahui bagaimana Implementasi pendidikan HAM dalam dunia pendidikan Sekolah Dasar. Metode yang digunakan adalah kualitatif deksriptif dengan pendekatan studi literatur. Berdasarkan hasil penelitian, peneliti mendapatkan jika Implementasi pendidikan HAM dalam dunia pendidikan Sekolah Dasar adalah cara dalam memperkanalkan anak pada paktek non-diskriminasi sejak dini dan juga menjadi cara dalam mengenalkan konsep HAM sejak dini pada anak. Kesimpulan penelitian ini adalah implementasi pendidikan HAM dalam dunia pendidikan Sekolah Dasar menjadi usaha dalam memberikan pendidikan HAM sejak dini.
\end{abstract}

Kata kunci: Pendidikan, HAM, Sekolah Dasar

\begin{abstract}
The implementation of human rights education in primary school education is an important part of primary school education. The purpose of this study is from the author's desire to find out how the implementation of human rights education in the world of elementary school education. The method used is descriptive qualitative with a literature study approach. Based on the results of the study, the researchers found that the implementation of human rights education in elementary school education is a way to introduce children to non-discrimination practices from an early age and also a way to introduce the concept of human rights to children from an early age. The conclusion of this study is that the implementation of human rights education in elementary school education is an effort to provide human rights education from an early age.
\end{abstract}

Keywords: Education, Human Rights, Elementary School

\section{PENDAHULUAN}

Manusia merupakan makhluk sosial yang tidak dapat hidup sendiri. Manusia selalu berinteraksi (Inah, 2013). Manusia adalah makhluk sosial, mereka suka melihat dan dilihat dan mencari tahu tentang orang lain (Maries, 2000). Ia selalu membutuhkan bantuan antar sesama makhluk hidup dengan tujuan agar bisa melangsungan kehidupan sehari harinya.

Setiap jenis sistem memiliki kelebihannya masing-masing (Lewis, 2013). Dalam ineraksi sistem manusia, manusia sejak diusia dini harus sudah diperkenalkan dengan adanya peran-peran penting dalam kehidupan diantaranya adalah peran Hukum dan Hak Asasi
Manusia agar terjadi keseimbangan atara hak hak tersebut dengan kehidupan.

Pada era globalisasi membutuhan generasi muda membutuhkan acuan yang dapat menjadikan mereka sebagai warga yang Baik (Ulfah et al., 2021). Hal tersebut tentunya sangat penting sekali untuk bekal diri dari setiap masing-masing individu agar belajar sejak dini dengan tujuan menjadi generasi penerus yang bisa dibanggakan dan mengharumkan nama baik suatu Negara.

Manusia adalah makhluk sosial, terlibat hampir secara konstan dalam perilaku sosial yang melayani tujuan sosial tertinggi, seperti membentuk ikatan yang kuat satu sama lain (Tamir \& Hughes, 2018). Proses pengenalan pada Hak Asasi 
Manusia perlu dilakukan sejak dini tidak terkecuali sejak di Sekolah Dasar. Haruskah bahwa beberapa diskusi pada anak-anak sekolah terjadi ketidaksepakatan (Wartenberg, 2012). Maka itu, dalam pengenalan pada Hak Asasi Manusia sejak dini adalah penting mengingat di Sekolah Dasar siswa memiliki pengetahuan yang menjadi dasar untuk selanjutnya.

Sebelum meninggalkan jabatannya pada tahun 2018, Komisaris Tinggi PBB untuk Hak Asasi Manusia, Zeid Ra'ad al Hussein, membuat serangkaian pernyataan kritis mengenai melemahnya mandat hak asasi manusia (Seiderman, 2019). Beberapa contoh mengenai kasus yang terdapat dugaan pelangaran HAM yang terhimpun dalam tirto.id oleh Murniaseh (2021) antara lain:

1. Peristiwa Trisakti yang menewaskan 4 mahasiswa

2. Peristiwa Semanggi yang menewaskan 6 orang

3. Peristiwa Semanggi II pada 24 September 1999

4. Kerusuhan Tanjung Priok pada 12 September 1984 yang menewaskan 24 orang

5. Peristiwa Talangsari pada 7 Februari 1989

Berdasarkan pada data dan fakta mengenai banyaknya kasus terdapat dugaan pelangaran HAM tersebut, maka sudah selayaknya bahwa implementasi pendidikan HAM dalam dunia pendidikan Sekolah Dasar adalah salah satu bagian yang penting dalam pendidikan di Sekolah Dasar.

Implementasi pendidikan Hak Asasi Manusia dalam dunia pendidikan Sekolah Dasar dapat menjadi awal perubahan yang dapat mendorong cita cita penegakan HAM. Gaffar (2006) mengatakan jika ada dua hal yang menjadi penentu dalam menghadapi transisi politik, yaitu tentang monopoli bisnis dan keadilan sosial. Kehidupan warga negara perlu di promosikan mengenai wacana global agar warga negara dapat memiliki pengetahuan yang tentang dunai global (Ali \& Hidayah, 2021).

Pendidikan Hak Asasi Manusia dalam dunia pendidikan Sekolah Dasar dapat dijadikan pranata dalam tiang perwujudan warga negara yang baik. Konsep spesifik domain yang sudah dipahami anak-anak dapat didalilkan (Goetzmann, 2017). Di Sekolah Dasar Sekolah Dasar adalah usaha yang teroraginsir dalam mengenalkan anak dalam oerientasi nilai-nilai keluruhan yang menjunjung tinggi harkat dan martabat manusia. Kesadaran mengenai tanggung jawab warga negara perlu di berikan pada warga negara (Hidayah et al., 6 C.E.).

Dengan melihat dari banyaknya mengenai kasus yang terdapat dugaan pelangaran HAM, diperlukan sosilisasi lebih luas mengenai kosep HAM. Diperlukan penguatan dalam meneguhkan nilai luhur bangs (Hidayah et al., 2021). Sudah seharusnya, penekanan pendidikan HAM memberikan wahana penegtahuan HAM pada warga negara secara holistik.

Rumusan masalah penelitian ini ialah"Bagaimana Implementasi pendidikan HAM dalam dunia pendidikan Sekolah Dasar?". Tujuan penelitian ini adalah mengetahui Implementasi pendidikan HAM dalam dunia pendidikan Sekolah Dasar. Manfaat teoritis penelitian adalah menjadi acuan dalam penelitian selanjutnya yang serupa. Manfaat secara parktis adalah menambah wawasan Implementasi pendidikan HAM dalam dunia pendidikan Sekolah Dasar.

\section{METODE PENELITIAN}

Metode yang digunakan oleh peneliti dalam tulisan ini adalah kualitatif studi literatur. Kualitatif adalah penelitian yang menghasilkan kata-kata (Moleong, 2007). Peneliti mempelajari refrensi yang berhubungan dengan implementasi pendidikan HAM dalam dunia pendidikan 
Sekolah Dasar adalah salah satu bagian yang penting dalam pendidikan di Sekolah Dasar.

Refrensi peneliti dapatkan dari sumber online dan offline baik dalam buku, artikel, jurnal, surat kabar dan lain lain yang masih berhubungan dengan implementasi pendidikan HAM dalam dunia pendidikan Sekolah Dasar adalah.

\section{HASIL PENELITIAN DAN PEMBAHASAN Hasil Penelitian}

Peneliti mendapatkan beberapa hasil penelitian mengenai implementasi pendidikan HAM dalam dunia pendidikan Sekolah Dasar yaitu jika Implementasi pendidikan HAM dalam dunia pendidikan Sekolah Dasar adalah cara dalam memperkanalkan anak pada paktek nondiskriminasi sejak dini dan juga menjadi cara dalam mengenalkan konsep HAM sejak dini pada anak.

Adapun Sekolah Dasar merupakan suatu lembaga pendidikan yang dijadikan tempat untuk pembelajaran dalam mengasah ilmu. Kemampuan,mengolah daya fikir dan lain sebagainya. Untuk itu siswa siswi di sekolah dasar harus diajarkan tentang pentingnya Hukum Dan Hak Asasi Manusia agar mereka tumbuh menjadi manusia yang taat akan hukum,menerapkan dan melindungi hak hak asasi yang ada demi mewujudukan-nya cita cita suatu Negara.

Hasil penelitian menunjukan jika Hak Asasi Manusia tentunya berlaku sama bagi semua orang khusunya bagi siswa siswi di Sekolah Dasar. Guru di Sekolah Dasar harus mampu menjelaskan apa itu pentingnya Hukum Dan Hak Asasi Manusia (Nurgiansah, 2020). Diera modern seperti saat ini,tentunya tindak kriminal dan kekerasan serta penyelewengan akan hukum sudah terjadi dan merajalela dimana - mana. Oleh karena itu ketika dilingkungan sekolah Dasar ini seorang guru harus bisa menciptakan siswa-siswi yang bermoral dengan menjamin setiap tindakan perbuatan dan perilakunya.

Lingkungan untuk membentuk watak dan karakter siswa siswi agar memiliki perilaku yang positif adalah dengan belajar dilingkungan sekolah maupun lingkungan keluarganya sendiri,karena lingkungan sangat berpengaruh bagi seorang siswa sebagai penunjang dalam proses berfikir dan proses pertumbuhannya masing masing. Oleh sebab itu baik orang tua maupun guru harus bisa bekerja sama dalam memberikan pengaruh yang positif khususnya

\section{Pembahasan}

Berdasarkan hasil penelitian bahwa implementasi pendidikan HAM dalam dunia pendidikan Sekolah Dasar adalah cara dalam memperkanalkan anak pada paktek non-diskriminasi sejak dini. Terdapat banyak kasus tentang hak-hak perempuan dan anak-anak internasional (Bunting, 2005). Jadi, dengan implementasi pendidikan HAM diharapkan anak akan memiliki pemahaman tentang paktek nondiskriminasi.

Pendidikan HAM pada menjadi cara dalam mengenalkan konsep HAM sejak dini pada anak. Membangun etika pada generasi muda penting dilakuan (Ulfah et al., 5 C.E.). Jadi dengan pendidikan HAM sejak dini pada diharapkan akan terbentuk mentalitas yang memiliki penghormatan pada hak asasi menusia.

Implementasi pendidikan HAM dalam dunia pendidikan Sekolah Dasar menjadi usaha dalam memberikan pendidikan HAM sejak dini. Kesadaran akan dominasi strategi hukuman penting untuk memastikan akses pembebasan dan penuh kasih (Handtke et al., 2016) (Dewantara et al., 2021). Dalam pendidikan HAM dalam dunia pendidikan Sekolah Dasar dapat juga memastikan akses pengetahuan siswa tentang HAM. 
Ketidaksetaraan kelas, usia dan sebagainya yang dihasilkan dari dunia global kontemporer telah menciptakan ketidakseimbangan struktural (Rowe, 2020) di sinilah, Posisi pendidikan HAM dalam dunia pendidikan Sekolah Dasar membantu penyelenggaraan kehidupan masyarakat yang bebas dari pelanggaran HAM.

Pengadopsian perjanjian-perjanjian inti hak asasi manusia internasional oleh negara-negara anggota ASEAN menghadirkan gambaran yang ambigu, yang mengungkapkan variasi yang signifikan antar negara (Rathgeber, 2014) (Nurgiansah, 2021). Pendidikan HAM di Sekolah Dasar merupakan upaya dalam memberikan pengetahuan pada generasi muda mengenai nilai-nilai luhur asasi manusia.

Kita harus memperhatikan impulsimpuls eksklusif yang terus mengancam untuk melemahkan realisasi penuh dari visi Deklarasi Universal Hak Asasi Manusia tentang perlindungan hak asasi manusia untuk semua, (Ibhawoh, 2014). Pendidikan HAM di Sekolah Dasar merupakan pendidikan yang dapat meminimalisir pelanggaran HAM, Yaitu dengan memberikna dasar mengenai HAM pada siswa.

\section{KESIMPULAN}

Kesimpulan artikel ini adalah Implementasi pendidikan HAM dalam dunia pendidikan Sekolah Dasar adalah salah satu bagian yang penting dalam pendidikan di Sekolah Dasar. Implementasi pendidikan HAM dalam dunia pendidikan Sekolah Dasar adalah cara dalam memperkanalkan anak pada paktek non-diskriminasi sejak dini dan juga menjadi cara dalam mengenalkan konsep HAM sejak dini pada anak. Implementasi pendidikan HAM dalam dunia pendidikan Sekolah Dasar menjadi usaha dalam memberikan pendidikan HAM sejak dini.

Penulis mengucapkan terimaksih kepada dosen pengampu mata kuliah pendidikan kewarganegaraan Ibu Yayuk Hidayah atas bimbingannya sehingga penulis dapat menyelesaikan penulisan artikel kolaborasi ilmiah ini.

\section{DAFTAR PUSTAKA}

Ali, Y. F., \& Hidayah, Y. (2021). Service-learning as a Strategy to Promote Global Citizenship in Indonesia. Society, 9(1).

Bunting, A. (2005). Stages of Development: Marriage of Girls and Teens as an International Human Rights Issue. Social \& Legal Studies, 14(1), 17-38. https://doi.org/10.1177/0964663905049524

Dewantara, J. A., Nurgiansah, T. H., \& Rachman, F. (2021). Mengatasi Pelanggaran Hak Asasi Manusia dengan Model Sekolah Ramah HAM (SR-HAM). Edukatif: Jurnal Ilmu Pendidikan, 3(2), 261-269.

Gaffar, A. (2006). Politik Indonesia; Transisi Menuju Demokrasi. Pustaka Pelajar.

Goetzmann, A. (2017). Elementary School Children's Political Knowledge. American Behavioral Scientist, 61(2), 238-253. https://doi.org/10.1177/0002764216689124

Handtke, V., Bretschneider, W., Elger, B., \& Wangmo, T. (2016). The collision of care and punishment: Ageing prisoners' view on compassionate release. Punishment \& Society, 19(1), 5-22. https://doi.org/10.1177/1462474516644679

Hidayah, Y., Suyitno, \& Ali, Y. F. (2021). A Study on Interactive-Based Learning Media to Strengthen the Profile of Pancasila Student in Elementary School. JED (Journal of Etika Demokrasi), 6(2).

Hidayah, Y., Trihastuti, M., \& Widodo, B. (6 C.E.). Online Learning Model in Improving Civic 
Responsibility as a Solution during Covid-19 Pandemic in Indonesia. Tadris: Jurnal Keguruan Dan Ilmu Tarbiyah, 1.

Ibhawoh, B. (2014). Human rights for some: Universal human rights, sexual minorities, and the exclusionary impulse. International Journal, 69(4), 612-622. https://doi.org/10.1177/0020702014544885

Inah, E. N. (2013). PERANAN KOMUNIKASI DALAM PENDIDIKAN. Jurnal Al-Ta'dib, 6(1).

Lewis, M. (2013). Human Interaction With Multiple Remote Robots. Reviews of Human Factors and Ergonomics, 9(1), 131-174. https://doi.org/10.1177/1557234X13506688

Maries, M. A. (2000). Pull Us Together or Push Us Apart?: Social and Cultural Implications of the Internet. Proceedings of the Human Factors and Ergonomics Society Annual Meeting, 44(2), 354. https://doi.org/10.1177/154193120004400216

Moleong, L. J. (2007). Metodologi Penelitian Kualitatif. PT Remaja Rosdakarya.

Murniaseh, E. (2021). Kasus Pelanggaran HAM di Indonesia \& Contohnya dalam Sejarah. Itrto.Id.

Nurgiansah, T. H. (2020). Filsafat Pendidikan. In Banyumas: CV Pena Persada.

Nurgiansah, T. H. (2021). Pendidikan Pancasila. In Solok: CV Mitra Cendekia Media.

Rathgeber, T. (2014). Documentation: International Legal Human Rights Framework: Human Rights and the Institutionalisation of ASEAN: An Ambiguous Relationship. Journal of Current Southeast Asian Affairs, 33(3), 131-165. https://doi.org/10.1177/186810341403300306

Rowe, D. (2020). Subjecting pandemic sport to a sociological procedure. Journal of Sociology, 56(4), 704-713. https://doi.org/10.1177/1440783320941284

Seiderman, I. (2019). The UN High Commissioner for Human Rights in the age of global backlash. Netherlands Quarterly of Human Rights, 37(1), 5-13. https://doi.org/10.1177/0924051918822854

Tamir, D. I., \& Hughes, B. L. (2018). Social Rewards: From Basic Social Building Blocks to Complex Social Behavior. Perspectives on Psychological Science, 13(6), 700-717. https://doi.org/10.1177/1745691618776263

Ulfah, N., Hidayah, Y., \& Trihastuti, M. (5 C.E.). URGENSI ETIKA DEMOKRASI DI ERA GLOBAL: MEMBANGUN ETIKA DALAM MENGEMUKAKAN PENDAPAT BAGI MASYARAKAT AKADEMIS MELALUI PENDIDIKAN KEWARGANEGARAAN. Jurnal Kewarganegaraan, 2.

Ulfah, N., Minasari, A., \& Hidayah, Y. (2021). Actualization of Pancasila in The Implementation of Ethical Democracy in The Global Era. Metafora: Education, Social Sciences and Humanities Journal.

Wartenberg, T. E. (2012). Elementary school philosophy: A response. Theory and Research in Education, 10(1), 89-96. https://doi.org/10.1177/1477878512437474 